\title{
The Impression of Enclosure in Persian Garden Design
}

\author{
Nafisi N, Abbas MY and Nafisi S \\ Faculty of Architecture, Planning \& Surveying, Universiti Teknologi MARA (UiTM), 40450 Shah Alam, Malaysia
}

\begin{abstract}
The presence of enclosure has been a significant characteristic of Persian gardens in Pre-Islamic and Islamic eras. This concept is also reflected in Persian ate miniature painting where buildings are enclosed by a light fence or a wall. In some cases, especially house gardens, the wall looks much stronger, probably to protect the security of the enclosed area. The organic arrangement of natural elements in the garden associated with the pavilion, however, is in contradiction to the presence of the enclosure. It can be said that in numerous paintings, water is not enclosed anymore, but it is the building (and the paved area close to it) that is covered by a transparent barrier or a well. Traditional Iranian towns highly appreciate the sense of privacy in their old building. For centuries, Iranian houses were divided into two parts "Inside" and "outside", in which family members solely used the first part while guests used the latter as well. Despite the importance of privacy in traditional Iranian culture, Iranian people were not isolated, and social contacts had an importance. In Persian garden can see two barriers: the decorated wall which separates the urban fabric from the garden and the fence which separates the paved area intended for sitting from the planted area. In this subject, it is appealing to see that these two enclosures divide the main frame into three layers of story in which three different groups of figures are located.
\end{abstract}

Keywords: Enclosure; Persian garden design; Miniature painting; Islamic era; Pavilion

\section{Introduction}

Iranian garden design it's often a mixture of architectural style, the garden style in Iran is proportionate to climate and water condition [1]. For Iranian, Persian gardens are a part of Iranian culture. The people of Iran have always desired to have a symbol of the heavens referred to as the paradise represented by the way they have structured their gardens. The gardens have remained green throughout the seasons despite the little water tapped from the melting snow on top of the mountains streaming down the valley. What has fascinated most is the art of creating the gardens in conceptual patterns. There are small gardens owned mostly by individuals or a family and due to an inadequate supply of water, they are unable to transform into plantations [2].

\section{Methodology}

This research, followed by a description of the process used to develop the survey questionnaire. The purposes of having a pilot study and the discussion of the results. Further, this Section describes the data collection.

\section{Structural Equation ModelLing (SEM)}

Structural Equation Modelling (SEM) analyzes encompass two major stages, the measurement model or confirmatory factor analysis (CFA) and the structural equation model. The measurement model (CFA model) is used to find out the links between manifest or observed and latent or unobserved variables. The measurement model could, therefore be said to define the manner in which latent or unobserved variables are assessed in terms of the manifest variables [3]. As suggested by Hair et al., individual CFA was performed for each of the constructs followed by the measurement model of study which provided specifics and evaluation based on the Goodness-Of-Fit (GOF) indices and evidence of construct validity [4]. This study employed the Maximum likelihood Estimation (MLE) as the extraction technique. This is one of the most widely used estimation methods that allow testing of individual direct effects and error term correlation.

One of the main advantages of the SEM is its ability to assess construct validity of measurements. In this instance, construct validity refers to the accuracy of measurements [4]. In SEM analyzes, construct validity is assessed by two main components, convergence validity, and discriminant validity. Convergent validity refers to the similarity in degree of variance between the items which are the indicators of a specific construct. The convergent validity could be measured by considering the size of factor loading (standardized regression weights), Average Variance Extracted (AVE), and construct reliability (CR) among sets of items in the construct. The factor loading estimates with values 0.5 or greater and extracted average variance of 0.5 or higher show adequate convergence among the items in the construct. The average variance extracted can be calculated by dividing the sum square of the standardized factor loading by the factor loading number. The construct reliability (CR) should be 0.6 or higher to show adequate internal consistency [5]. The CR is computed from the square sum of factor loading and sum of error variance terms for a construct. CR can be calculated using the following formula (Figure 1).

\section{Privacy (PRVC) has a positive effect on the willingness to Persian garden}

As shown in Table 1, the C.R and p-value of Privacy (PRVC) in predicting Willingness to Persian Garden were 6.146 and 0.000 respectively. It means that the probability of getting a critical ratio as large as 6.146 in absolute value is 0.000 . In other words, the regression weight for Privacy (PRVC) in the prediction of Willingness Persian garden. Is significantly different from zero at the 0.001 level (twotailed). Further, the standardized estimate of Beta was 0.317 , indicating

*Corresponding author: Nazanin Nafisi, Faculty of Architecture, Planning and Surveying, Universiti Teknologi MARA (UiTM), 40450 Shah Alam, Selangor, Malaysia, Tel: 60355442000; E-mail: n.nazanin67@gmail.com

Received January 28, 2016; Accepted March 11, 2016; Published March 21 2016

Citation: Nafisi N, Abbas MY, Nafisi S (2016) The Impression of Enclosure in Persian Garden Design. J Steel Struct Constr 2: 108. doi:10.4172/24720437.1000108

Copyright: @ 2016 Nafisi N, et al. This is an open-access article distributed under the terms of the Creative Commons Attribution License, which permits unrestricted use, distribution, and reproduction in any medium, provided the original author and source are credited. 


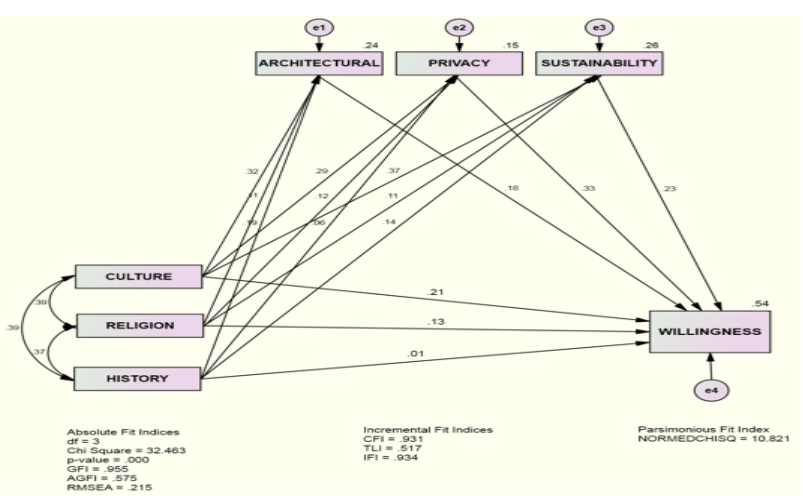

Figure 1: Structural model

\begin{tabular}{|l|c|c|c|c|c|c|}
\hline \multicolumn{1}{|c|}{ Path } & \multicolumn{2}{|c|}{$\begin{array}{c}\text { Unstandardized } \\
\text { Estimate }\end{array}$} & $\begin{array}{c}\text { Standardized } \\
\text { Estimate }\end{array}$ & C.R. & P-value & Hypothesis \\
& Estimate & S.E. & Beta & & & \\
\hline CULT $\rightarrow$ SHGA & 0.218 & 0.061 & $0.203^{* *}$ & 3.581 & 0.000 & H1) Supported \\
\hline RELG $\rightarrow$ SHGA & 0.122 & 0.051 & $0.122^{*}$ & 2.362 & 0.018 & H2) Supported \\
\hline HIST $\rightarrow$ SHGA & 0.005 & 0.054 & 0.005 & 0.101 & 0.919 & H3) Rejected \\
\hline ARCH $\rightarrow$ SHGA & 0.182 & 0.055 & $0.178^{* * *}$ & 3.292 & 0.000 & H4) Supported \\
\hline PRVC $\rightarrow$ SHGA & 0.288 & 0.047 & $0.317^{* *}$ & 6.146 & 0.000 & H5) Supported \\
\hline SUST $\rightarrow$ SHGA & 0.23 & 0.056 & $0.226^{* *}$ & 4.075 & 0.000 & H6) Supported \\
\hline
\end{tabular}

Contribution is significant at the 0.05 level (2-tailed); ${ }^{* * *}$ Contribution is significant at the 0.001 level (2-tailed).

Table 1: Standardized regression weights in structural model.

a positive relationship. It means, when Privacy (PRVC) goes up by 1 standard deviation, Willingness to Persian garden goes up by 0.317 standard deviations.

Furthermore, amongst the six predictors of Willingness to Persian garden, Privacy (PRVC) was found as the most important influential factor, with the standardized estimate of 0.317 (Table 1).

The sense of enclosure: The presence of enclosure has been a significant characteristic of Persian gardens in Pre-Islamic and Islamic eras [6]. This concept is also reflected in Persian ate miniature painting where buildings are enclosed by a light fence or a wall. In some cases, especially house gardens, the wall looks much stronger, probably to protect the security of the enclosed area. The organic arrangement of natural elements in the garden associated with the pavilion, however, is in contradiction to the presence of the enclosure. It can be said that in numerous paintings, water is not enclosed anymore, but it is the building (and the paved area close to it) that is covered by a transparent barrier or a well. This wall becomes a formal device for the artist to frame and captures the social events and the interactions in the garden. The wall and barrier are present in the story of Iskandar and the seven sages, attributed to Bihzad from the Khamsah by Nezami (Timurid, Herat, 1494-5 AD). Here can see two barriers: the decorated wall which separates the urban fabric from the garden and the fence which separates the paved area intended for sitting from the planted area. In this subject, it is appealing to see that these two enclosures divide the main frame into three layers of story in which three different groups of figures are located (Figure 2).

Privacy: Traditional Iranian towns highly appreciate the sense of privacy in their old building. For centuries, Iranian houses were divided into two parts "Inside" and "outside", in which family members solely used the first part while guests used the latter as well. Despite the importance of privacy in traditional Iranian culture, Iranian people were not isolated, and social contacts had a great importance [7]. The varying degree of connection between the inside and outside of the pavilion and even within the garden affects the levels of privacy in the Persian garden and pavilion. Three types of connection are established between the garden and pavilion: physical, visual, and symbolic. The changing level of physical connection between areas in the garden and between the garden and building is a tool for the artist to define the hierarchy and privacy. For example, the king's throne is supposed to be the least accessible to other people whereas the paved area next to the pavilion is quite accessible to courtiers and servants. The visual (and formal) connection forges through the use of color, decorative patterns, and vertical and horizontal composition of elements. Artists also use landscape elements such as a fence, pool, and trees to define the visual connection with the garden [8]. For instance, in a painting of Sultan Muhammad in Diwan Hafez from the 16th century, the fence separates the workers from the royals. In this painting, workers are working in the planted area, while the members of the court are in the paved area as a private space. In this painting, fence is used to enhance the privacy of the kings and queens from the workers. This separation and privacy can be seen in other miniatures from Khosrow and Shirin, and Humay, and Humayun, in which while the ladies are looking down from the balcony or the roof, they are invisible from the people who are in the garden. Sometimes this connection is more in symbols and iconic, and less visible. This trick can be seen in a painting from Haft Awrang, in which the fallen lover is somewhat connected to the roof and the ground, as these two are connected. This also indicates the importance of the location of the story (roof and garden) [9]. Why should issues of privacy be thus emphasized in painting? As a cultural issue, privacy stems from the interrelated social phenomena of segregation of men and women and exceptional status of the royal family in the Persian society. It can be seen in a Mughal painting from the Hamzanama (1564-1569 AD), the garden is only used by Mihrdukht and other royal women, who are shooting from the second floor balcony, Despite its fundamental differences with Persian paintings (especially in depicting spaces and figures), this painting clearly shows the concepts of gender specificity and segregation. At the same time, hierarchy is also visible among women depicted in the painting. While the higher class women are on the second floor, the lower level, including servants (and gardener), are on the first floor (Figure 3) [10].

Gender segregation: Lisa Golombek in "The Gardens of Timur: New Perspectives," speaks about a 'gendered' history behind the creation of Timurid gardens. Based on several Timurid references, she concludes that there is a strong link between the design of gardens and the history of women associated with it. This phenomenon can be seen in several paintings in which women play a substantial role in narratives as primary or secondary figures. At the same time, one

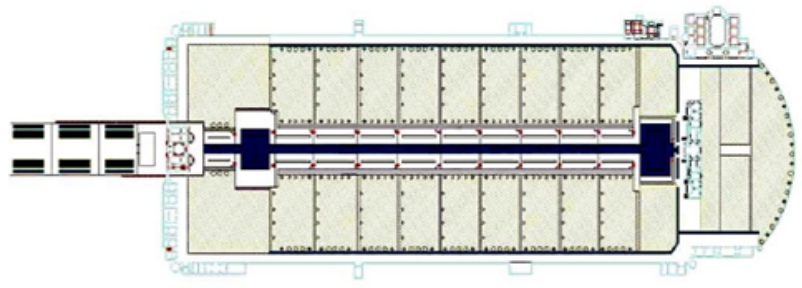

Figure 2: Wall around the shazdeh garden. 


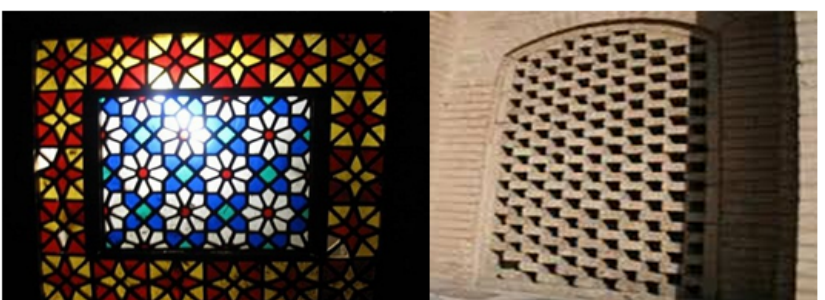

Figure 3: Design windows for protection privacy in persianbuildings.

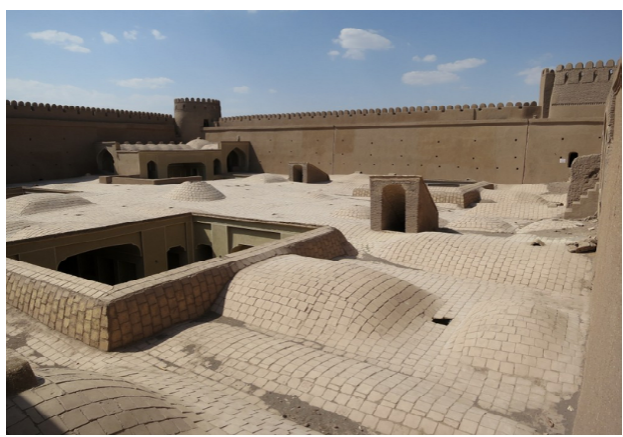

Figure 4: Wall surround the pavilion.

of the major similarities between scenes depicted in Persian miniature painting is the segregation of men and women. In terms of social interactions, the garden is formally or physically divided into male and female areas. This gender segregation works as a tool to protect the privacy of women and the hierarchy of people within the scene. It also relates to the cultural value of hijab and the intimacy of the women within the family and society [10].

Pavilion as a building in the garden: In miniature painting, the building in relation to the garden is depicted in three forms: a pure volume which is surrounded by a garden, a background for the garden, and a foreground of the garden. Gardens in Persian painting are in two types; social types, and private types. The first type illustrates the social events taking place in the garden while the latter looks at the family affairs, and private residence [11]. The social types look at the building as the core of the painting, and put the value of it as a solid element while the private gardens are a portrayal of interior space, and Iwan, the intermediate and semi-open space between the building and garden. In these painting, one can understand the position of the painter, inside or outside the buildings, as well as its point of view. In some cases, the walls of the building are removed to illustrate the private matters in the house from a point of view outside the house and in the garden, Sultan Muhammad (active 1505-1550 AD). This allows the painter to change the elements of the painting and create a new point of view (Figure 4) [12].

\section{Discussion of the Findings}

There were six hypotheses developed to test the antecedents and outcomes of Persian garden willingness. Based on the results, culture significantly associated with Persian garden. Findings from this research supported the hypothesized relationship between the Persian garden and privacy; in fact, these results confirmed the hypothesized positive relationship between privacy. Also, Persian garden was significantly associated with sustainability Overall, the results appeared to partly support the concept of culture in social cognitive theory which views that conduct, cognitive and another personal agents, and environmental (regional) penetration all function interactively as factor of each other [13]. From the perspective of culture, is viewed as a result of the interaction of personal, behavioral, and regional influences. Accordingly, in this research, culture was found to be associated with the social aspect, namely, that leads to behavior factor (privacy and custom) In other words, the interactions of cultural, behavioral and regional influences may, in fact, behind the creation of Persian garden behavioral factors are significant than other factors.

\section{Conclusion}

Thus, it can be concluded that walking and leisure are linked to each other in Iranian lifestyle culture and to integrate the issues of privacy, religion [14]. This could be provoked by linear forms of urban spaces as well. In this part, the notion of privacy will be discussed generally. Also, the predominant theories related to the privacy concept will be discussed. As per the Encyclopedia Britannica, privacy is defined as the state of quality of being away from observation or corporation. As an act, privacy gives freedom from intrusions of unauthorized nature. Another definition defines privacy as a secluded place. The Webster web dictionary also gives a similar definition for privacy. As such privacy is defined as the quality of being secluded from the current or the capture of others or the condition of being hidden or concealed [Webster online dictionary, 2006] [15]. The term seclusion and the presence or catch of others are contrasted and correlated with the term privacy. It is also contrasted with the terms social, public, community, etc. as per Westin (1967), privacy is defined as the claim of people, institutions or groups for determining for themselves, how, when and to what kind of information regarding them is communicated to others. From the viewpoint of linking individuals with their social participation, privacy is defined as the voluntary as well as the provisional withdrawal of an individual from the general social engagements via physical or psychological ways, either in a solitude state or small group sincerity or when with big groups, in a situation of reserve or anonymity. Predicted to aid garden design with a sustainable design more effectively. Therefore, understanding Persian garden design among culture could be a valuable research field to venture into in the future.

\section{References}

1. Nafisi N, Abbas Y (2014) Study of Persian Garden Structure from Cultural Impact. Proceedings Book of ICETSR, Malaysia Handbook on the Emerging Trends in Scientific Research, Malaysia.

2. Kiani M (2004) Iranian Architecture during the Islamic Period. Tehran: Tehran Publishers.

3. Ho R (2006) Handbook of univariate and multivariate data analysis and interpretation with SPSS. United States of Americ: Chapman and Hall/CRC, Taylor and Francis Group.

4. Hair JF, Black WC, Babin BJ, Anderson RE, Tatham RL (2006) Multivariate data analysis. ( $6^{\text {th }}$ ed) Upper Saddle River, Pearson prentice hall, NJ, United State of America.

5. Bagozzi RP, Yi Y (1988) On the evaluation of structural equation models Journal of Academy of Marketing Science 16: 74-94.

6. Nafisi N, Abbas Y, Nafisi S (2015) The Role of Belief and Religion in Creation of Persian Garden. Journal of Architectural Engineering Technology 4: 1-5.

7. Ramezani S (2010) Privacy and Social Interaction in Traditional Towns to Contemporary Urban Design in Iran. American Journal of Engineering and Applied Sciences 3: 501-508.

8. Pope AU, Ackerman P, Besterman T (1964) Survey of Persian Art. Oxford university press. 
Citation: Nafisi N, Abbas MY, Nafisi S (2016) The Impression of Enclosure in Persian Garden Design. J Steel Struct Constr 2: 108. doi:10.4172/24720437.1000108

9. Kive MS (2012) The Other Space of Persian Garden. An Interdisciplinary Arts and Sciences Journal 2: 85-96.

10. Gharipour M (2014) The Genesis In Thought And Ideas Behind The Design Of The Mughal Gardens In India. University of North Carolina - Charlotte, USA.

11. Sardar Z (2011) Inspiration for Private Paradises, 38 Keyes Avenue, Suite 106, San Francisco, CA.
12. Gharipour M (2013) Persian Gardens and Pavilions: Reflections in History, Poetry and the Arts. I. B. Tauris.

13. Bandura A (1989) Social cognitive theory. In Vasta R (Ed), Annals of child development 6: 1-60.

14. Rapaport A (2007) The nature of the courtyard house: A conceptual analysis. Traditional Dwellings and Settlements Review 18: 57-71.

15. Webster online dictionary, 2006. 